\title{
Effects of photoperiod and temperature on the induction of adult diapause in Dolycoris baccarum (L.) (Heteroptera: Pentatomidae) from Osaka and Hokkaido, Japan
}

\author{
Keiji NAKAMURA ${ }^{* \dagger}$ and Hideharu NumATA \\ Department of Biology and Geosciences, Graduate School of Science, Osaka City University; Osaka 558-8585, Japan
}

(Received 25 May 2005; Accepted 5 October 2005)

\begin{abstract}
Effects of photoperiod and temperature on the induction of adult diapause were examined in Dolycoris baccarum (L.) collected in Osaka and Hokkaido, Japan. Adults started reproduction soon after adult emergence under long-day conditions, while they entered diapause under short-day conditions. The critical photoperiod for the induction of diapause was between 13 and $14 \mathrm{~h}$ and between 15 and $16 \mathrm{~h}$ in insects of the Osaka and Hokkaido populations, respectively. Under long-day conditions, most insects of the Osaka population emerged as reproductive adults at any temperature used, whereas those in the Hokkaido population tended to show lower incidence of diapause as the temperature increased. Preoviposition periods in females of the Osaka population were shorter than those of the Hokkaido population. The duration of diapause in the Osaka population was shorter at $30^{\circ} \mathrm{C}$ than at $25^{\circ} \mathrm{C}$ under short-day conditions. In Osaka, D. baccarum is assumed to produce three generations a year, like several other seed-sucking bugs. In Hokkaido, a greater proportion of adults produces the second generation in summer under long daylengths.
\end{abstract}

Key words: Dolycoris baccarum; adult diapause; photoperiod; temperature; geographical variation

\section{INTRODUCTION}

Dolycoris baccarum is a polyphagous seedsucking bug that is distributed widely in the Palearctic region, and causes damage to a variety of crops (Panizzi et al., 2000). Also in Japan, D. baccarum is known as a pest on several plants such as soybeans, cotton, sesame, carrots, burdock and rice (Tomokuni et al., 1993). In Europe, the lifecycle adaptations in $D$. baccarum have been studied extensively (Kamenkova, 1958; Perepelitza, 1969; Conradi-Larsen and Sømme, 1973, 1978; Hodek, 1977; Karsavuran, 1986; Babrakzai and Hodek, 1987; Hodková et al., 1989; Hodek and Hodková, 1993). This species has a multivoltine lifecycle in the Krasnodar territory, Russia, and a univoltine lifecycle in high latitude regions such as Novosibirsk and Primorsk, Russia and southern Norway (Perepelitza, 1969; Conradi-Larsen and Sømme, 1973). Adult winter diapause is induced and averted by short- and long-day conditions, respec- tively (Babrakzai and Hodek, 1987; Hodková et al., 1989; Hodek and Hodková, 1993).

By contrast, the lifecycle of $D$. baccarum in Japan has not been studied extensively. In central Hokkaido, a northern island of Japan, D. baccarum is observed from May to July and in October (Hori, 1984). Kobayashi (1972) suggested that D. baccarum has a bivoltine lifecycle in southwestern Japan. However, no experimental study has been made to examine the lifecycle of $D$. baccarum in Japan. Our preliminary observations showed that D. baccarum appeared continuously from spring to late autumn in Osaka, and that many adults entered diapause in August in eastern Hokkaido. In the present study, we collected D. baccarum from Osaka and eastern Hokkaido, and kept insects from eggs under various combinations of photoperiod and temperature. Results in the two populations were compared, and the lifecycle adaptations in this species were inferred from these findings.

\footnotetext{
* To whom correspondence should be addressed at: E-mail: nakamura@big.ous.ac.jp

$\dagger$ Present address: Department of Biosphere-Geosphere System Science, Faculty of Informatics, Okayama University of Science, Okayama 700-0005, Japan

DOI: 10.1303/aez.2006.105
} 


\section{MATERIALS AND METHODS}

Adults of $D$. baccarum were collected from the fields in Tokoro, Hokkaido $\left(44.2^{\circ} \mathrm{N}, 144.0^{\circ} \mathrm{E}\right)$ and Osaka $\left(34.7^{\circ} \mathrm{N}, 135.5^{\circ} \mathrm{E}\right)$, Japan from June to September 1996. Insects were reared as male-female pairs in plastic cups $(60 \mathrm{ml})$ on raw peanuts and water. Eggs laid by the field-collected adults were placed under experimental conditions within $24 \mathrm{~h}$ of oviposition. Nymphs were reared in plastic cups $(200 \mathrm{ml})$. In one set of experiments, insects were kept under 18L : 6D (18 h light: $6 \mathrm{~h}$ dark), 16L : 8D, $15 \mathrm{~L}: 9 \mathrm{D}, 14 \mathrm{~L}: 10 \mathrm{D}, 13 \mathrm{~L}: 11 \mathrm{D}$ or $12 \mathrm{~L}: 12 \mathrm{D}$ at $25 \pm 1{ }^{\circ} \mathrm{C}$ to examine the effect of the photoperiod. In the other set of experiments, insects were kept under long-day (16L : 8D) or short-day (12L: 12D) conditions at $30 \pm 1,27.5 \pm 1,25 \pm 1$ and $20 \pm 1{ }^{\circ} \mathrm{C}$. Mortality and oviposition of adults were recorded every day. Some adults were kept continuously under 12L:12D for $120 \mathrm{~d}$. The other adults were dissected $30 \mathrm{~d}$ after emergence, and the diapause status was judged by the criteria used for Eurydema rugosum, Aelia fieberi and Dybowskyia reticulata (Numata and Yamamoto, 1990; Nakamura and Numata, 1997, 1998). According to these criteria, females without mature eggs or vitellogenic oocytes in the ovarioles and males without secretory fluid in the ectodermal sac of the accessory gland were considered to be in diapause.

\section{RESULTS}

\section{Effect of photoperiod on the induction of adult diapause}

All or most females of the Osaka population reared from eggs in the laboratory under $16 \mathrm{~L}: 8 \mathrm{D}$, 15L : 9D and $14 \mathrm{~L}: 10 \mathrm{D}$ at $25^{\circ} \mathrm{C}$ started oviposition soon after adult emergence (Fig. 1). There was no significant difference in the pre-oviposition period among the three photoperiods (Kruskal-Wallis test, $p>0.05$ ). All females including those that did not start oviposition within $30 \mathrm{~d}$ had mature eggs or vitellogenic oocytes (Fig. 2). Under L13:D11, no female started oviposition within $30 \mathrm{~d}$ (Fig. 1), but $29.2 \%$ of them had mature eggs or vitellogenic oocytes (Fig. 2). Under 12L : 12D, all insects were in diapause. There was no significant difference in the incidence of diapause between sexes under each photoperiod (Fisher's exact probability test, $p>0.05)$.
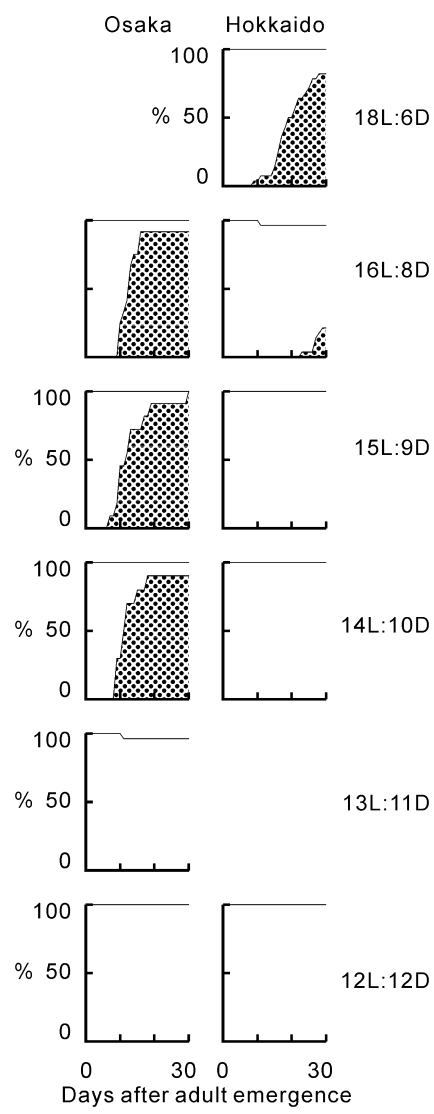

Fig. 1. Effects of photoperiod on survival and oviposition in females of Osaka and Hokkaido populations of Dolycoris baccarum at $25^{\circ} \mathrm{C}$. Dotted areas, percentage of cumulative ovipositing females; open areas, percentage of non-ovipositing females. $N=9-33$.

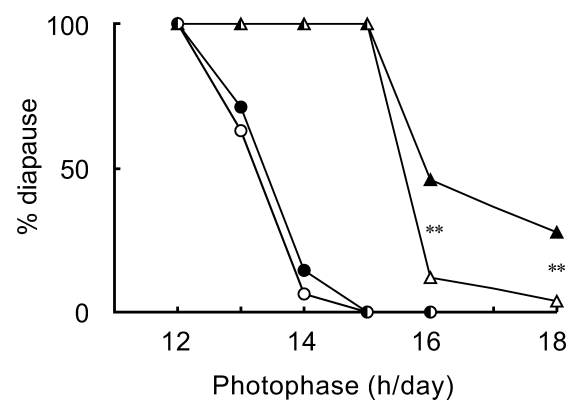

Fig. 2. Photoperiodic response curves for the induction of adult diapause in Dolycoris baccarum of Osaka and Hokkaido populations at $25^{\circ} \mathrm{C}$. Open circles, female adults of the Osaka population; closed circles, males of the Osaka population; open triangles, female adults of the Hokkaido population; closed triangles, males of the Hokkaido population. $N=7-48$. Asterisks indicate significant differences in the incidence of diapause between sexes. ${ }^{* *} p<0.01$ (Fisher's exact probability test). 
Most females of the Hokkaido population kept continuously from eggs under $18 \mathrm{~L}: 6 \mathrm{D}$ at $25^{\circ} \mathrm{C}$ started oviposition (Fig. 1). Their preoviposition period was significantly longer than that in females of the Osaka population under 16L:8D (MannWhitney's $U$-test, $p<0.01)$. Many females did not start oviposition within $30 \mathrm{~d}$ under 16L : 8D (Fig. 1 ), although most of them had mature eggs or vitellogenic oocytes (Fig. 2). The incidence of diapause in females was significantly higher than that in males under 16L:8D and 18L:6D (Fisher's exact probability test, $p<0.01)$. Under $15 \mathrm{~L}: 9 \mathrm{D}$, $14 \mathrm{~L}: 10 \mathrm{D}$ or $12 \mathrm{~L}: 12 \mathrm{D}$, all insects were in diapause.

\section{Effect of temperature on the induction of adult diapause}

We examined the effects of temperature and

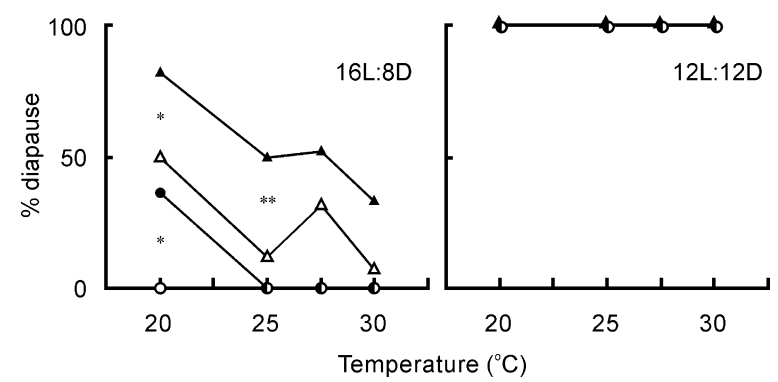

Fig. 3. Effects of temperature on the induction of adult diapause under long-day and short-day conditions in Osaka and Hokkaido populations of Dolycoris baccarum. Open circles, female adults of the Osaka population; closed circles, males of the Osaka population; open triangles, female adults of the Hokkaido population; closed triangles, males of the Hokkaido population. $N=8-33$. Asterisks indicate significant differences in the incidence of diapause between sexes. $* p<0.05$, $* * p<0.01$ (Fisher's exact probability test). photoperiod on the induction of diapause. Under $16 \mathrm{~L}: 8 \mathrm{D}$, insects of the Osaka population became reproductive regardless of temperature except for males at $20^{\circ} \mathrm{C}$ (Fig. 3). The incidence of diapause in females was significantly higher than that in males at $20^{\circ} \mathrm{C}$ (Fisher's exact probability test, $p<0.05$ ). In both males and females of the Hokkaido population, the incidence of diapause under the long-day conditions was significantly different among temperatures (chi-square test, $p<0.01)$. There was a tendency for higher temperatures to lower the incidence of diapause. The incidence of diapause was significantly higher than that in males at $25^{\circ} \mathrm{C}$ (Fisher's exact probability test, $p<0.01)$ and at $20^{\circ} \mathrm{C} \quad(p<0.05)$. Under $12 \mathrm{~L}: 12 \mathrm{D}$, diapause was induced regardless of temperature in both populations.

\section{Effect of temperature on the termination of adult diapause}

When insects from eggs were continuously kept under $12 \mathrm{~L}: 12 \mathrm{D}$ at $30^{\circ} \mathrm{C}$, all females of the Osaka population started oviposition by $70 \mathrm{~d}$ after adult emergence (Fig. 4). At $25^{\circ} \mathrm{C}$, the preoviposition period was significantly longer than that at $30^{\circ} \mathrm{C}$ (Mann-Whitney's $U$-test, $p<0.01$ ). In the Hokkaido population, more than half of the females at $30^{\circ} \mathrm{C}$ died within $120 \mathrm{~d}$, and about half of the surviving females started oviposition. The preoviposition period was significantly longer than that in the Osaka population under the same conditions (Mann-Whitney's $U$-test, $p<0.01$ ). At $25^{\circ} \mathrm{C}$, only one of $21 \mathrm{fe}$ males started oviposition within the experimental period.
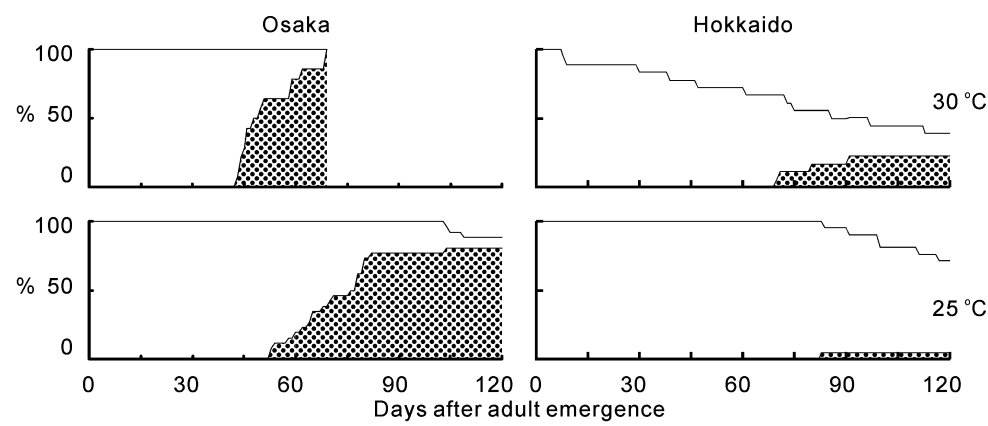

Fig. 4. Effects of temperature on survival and oviposition in adults of Osaka and Hokkaido populations of Dolycoris baccarum under short-day conditions (12L : 12D). Dotted areas, cumulative percentage of ovipositing females; open areas, percentage of non-ovipositing females. $N=14-26$. 


\section{DISCUSSION}

Adults of $D$. baccarum reproduced under longday conditions but entered diapause under shortday conditions. European populations of $D$. baccarum have also been reported to show this type of response (Babrakzai and Hodek, 1987; Hodková et al., 1989; Hodek and Hodková, 1993). In the Osaka population, the critical photoperiod for the induction of diapause was between 13 and $14 \mathrm{~h}$ at $25^{\circ} \mathrm{C}$ (Fig. 2). Daylengths including $0.5 \mathrm{~h}$ twilight periods in Osaka are about $13 \mathrm{~h}$ in early September. In Osaka, therefore, D. baccarum probably reproduces in spring and summer, and adults emerging in September or later enter winter diapause. Several other heteropterans of central Japan have critical daylengths of 13 to $14 \mathrm{~h}$ for the induction of adult diapause, e.g., Riptortus clavatus (Kobayashi and Numata, 1993) and Plautia crossota stali (Numata and Kobayashi, 1994). These bugs were assumed to produce three generations a year (Numata and Nakamura, 2002). From the present results, we suggest that $D$. baccarum has a similar lifecycle in Osaka. However, Kobayashi (1972) reported that D. baccarum might have a bivoltine lifecycle in southwestern Japan because insects were found twice in the spring and autumn. Many adults of $D$. baccarum were parasitized by tachinid flies in the summer, although no parasitism was recorded before overwintering in Morioka, Iwate Prefecture, Japan (Honda, 1985). It is possible that the mortality of D. baccarum during the summer is also high in Osaka because of parasitism, and the high mortality makes it difficult to find insects during the summer.

In the Hokkaido population, adult diapause was averted under $16 \mathrm{~L}: 8 \mathrm{D}$ or longer photoperiods at $25^{\circ} \mathrm{C}$, showing that insects can produce more than one generation a year. Hori (1984) reported that $D$. baccarum was observed from May to July and in October in central Hokkaido, suggesting that the insect has a bivoltine lifecycle. This observation is not in conflict with the present findings that adults started reproduction under long-day photoperiods at high temperatures. However, we cannot exclude the possibility that a partial bivoltine lifecycle might be common in eastern Hokkaido because adults of the first generation collected in August in 1996, 1998 and 2000 were in diapause (Nakamura, unpublished). Even if some adults of the first gen- eration enter diapause in eastern Hokkaido, a certain proportion of insects can reproduce in the summer under long daylengths.

The critical photoperiod in the Hokkaido population was between 15 and $16 \mathrm{~h}$, which was longer by $2 \mathrm{~h}$ than that in the Osaka population (Fig. 2). In many insect species, populations at higher latitudes have longer critical daylengths for the induction of diapause (Danilevskii, 1961; Tauber et al., 1986; Danks, 1987). The present study exhibits that $D$. baccarum shows a similar geographical cline for the induction of adult diapause. The critical photoperiod increases about $1 \mathrm{~h} / 5^{\circ}$ of latitude in many insects (Danilevskii, 1961; Danks, 1987). In Cletus punctiger (Heteroptera: Coreidae), the critical photoperiod is $12 \mathrm{~h}$ in Ishigaki $\left(24.3^{\circ} \mathrm{N}\right)$, between 13 and $14 \mathrm{~h}$ in Fukuyama $\left(34.5^{\circ} \mathrm{N}\right)$ and Tsukuba $\left(36.0^{\circ} \mathrm{N}\right)$, and $14.5 \mathrm{~h}$ in Shiraishi $\left(38.0^{\circ} \mathrm{N}\right)$ (Ito, 1989). The increase in critical photoperiod is $1 \mathrm{~h} / 5.48^{\circ}$ in $C$. punctiger. From the present results, the difference in the critical photoperiod in D. baccarum is $1 \mathrm{~h} / 4.75^{\circ}$ of latitude, which is slightly less than that in C. punctiger. Because the cline is similar to many other insects, the timing of diapause induction in $D$. baccarum has a close relation to the arrival of winter in each locality. The cline can also be applied to the insects of Europe. In the population from southern Norway $\left(61^{\circ} 30^{\prime} \mathrm{N}\right)$ where the longest photophase is more than $22 \mathrm{~h}$, all adults reproduce under constant 18L : 6D (Hodková et al., 1989), but diapause is induced under $16 \mathrm{~L}: 8 \mathrm{D}$ (Conradi-Larsen and Sømme, 1978). These findings show that $D$. baccarum has adapted to local climates by changing its photoperiodic response for the induction of adult diapause.

Temperature can modify the photoperiodic responses in D. baccarum of European populations (Conradi-Larsen and Sømme, 1978; Hodek and Hodková, 1993). Most insects of a population from southern Norway entered diapause under 16L : 8D or $8 \mathrm{~L}: 16 \mathrm{D}$ at $21^{\circ} \mathrm{C}$, whereas more than half of the adults started oogenesis within $18 \mathrm{~d}$ when the temperature was increased from 21 to $30^{\circ} \mathrm{C}$ after adult emergence, in either long-day or short-day conditions (Conradi-Larsen and Sømme, 1978). In a population from Prague $\left(52^{\circ} \mathrm{N}\right)$, Czech Republic, more than half of the females oviposited even under short-day conditions when reared at $26^{\circ} \mathrm{C}$ or after an increase in temperature from $20^{\circ} \mathrm{C}$ to $26^{\circ} \mathrm{C}$ (Hodek and Hodková, 1993). In the present study, 
lower temperatures tended to induce diapause under $16 \mathrm{~L}: 8 \mathrm{D}$, especially in the Hokkaido population (Fig. 3). In contrast, high temperatures such as 27.5 or $30^{\circ} \mathrm{C}$ did not avert diapause under $12 \mathrm{~L}: 12 \mathrm{D}$, contrary to the results in European populations. However, the duration of diapause under the short-day conditions was significantly shorter at $30^{\circ} \mathrm{C}$ in the Osaka population (Fig. 4). Therefore, even if high temperature does not avert diapause, it may accelerate diapause development.

\section{ACKNOWLEDGEMENTS}

We thank Y. Kida of Maruseppu Town Insectarium for assistance in the collection of insects.

\section{REFERENCES}

Babrakzai, Z. H. and I. Hodek (1987) Diapause induction and termination in a population of Dolycoris baccarum (Heteroptera, Pentatomoidea) from Central Bohemia. Vest. Cs. Spolec. Zool. 51: 85-88.

Conradi-Larsen, E.-M. and L. Sømme (1973) Notes on the biology of Dolycoris baccarum L. (Het., Pentatomidae). Norsk Entomol. Tidsskr. 20: 245-247.

Conradi-Larsen, E.-M. and L. Sømme (1978) The effect of photoperiod and temperature on imaginal diapause in Dolycoris baccarum from southern Norway. J. Insect Physiol. 24: 243-249.

Danilevskii, A. S. (1961) [Hidaka, T. and S. Masaki Japanese translation, 1966] Photoperiodism and Seasonal Development of Insects. University of Tokyo Press, Tokyo. $293 \mathrm{pp}$.

Danks, H. V. (1987) Insect Dormancy: An Ecological Perspective. Biological Survey of Canada, Ottawa. $439 \mathrm{pp}$.

Hodek, I. (1977) Photoperiodic response in spring in three Pentatomoidea (Heteroptera). Acta Entomol. Bohemoslov. 74: 209-218.

Hodek, I. and M. Hodková (1993) Role of temperature and photoperiod in diapause regulation in Czech populations of Dolycoris baccarum (Heteroptera: Pentatomidae). Eur. J. Entomol. 90: 95-98.

Hodková, M., I. Hodek and L. Sømme (1989) Cold is not a prerequisite for the completion of photoperiodically induced diapause in Dolycoris baccarum from Norway. Entomol. Exp. Appl. 52: 185-188.

Honda, K. (1985) A note on Cylindromyia brassicaria (Fabr.) (Diptera: Tachinidae), a parasite of the sloe bug, Dolycoris baccarum Linnaeus (Hemiptera: Pentatomidae). Jpn. J. Appl. Entomol. Zool. 29: 78-80 (in Japanese with English summary).

Hori, K. (1984) Hemiptera in East Taisetsu. In Biological Fauna of East Taisetsu Region. Vol. 2 (H. Nishijima ed.). Nukabira Biological Research Institute, Obihiro Univer- sity of Agriculture and Veterinary Medicine, Obihiro, pp. 19-34.

Ito, K. (1989) Studies on the life history of Cletus punctiger Dallas (Heteroptera: Coreidae) with special reference to the seasonal interhabitat movements and mechanism of immigration into rice fields. Bull. Natl. Agric. Res. Cent. 14: 39-103 (in Japanese with English summary).

Kamenkova, K. V. (1958) Biology and ecology of berry bug, Dolycoris baccarum L. an auxiliary host for the stink bug egg-eater in Krasnodar territory. Entomol. Rev. 37: 487-500.

Karsavuran, Y. (1986) Investigations on the biology and ecology of Dolycoris baccarum (L.) (Het.: Pentatomidae) which attacks to the various plants of economic importance at Bornova (Izmir.). Türk. Bitki Kor. Derg. 10: 213-230 (in Turkish with English summary).

Kobayashi, T. (1972) Biology of insect pests of soybean and their control. Jpn. Agric. Res. Quart. 6: 212-218.

Kobayashi, S. and H. Numata (1993) Photoperiodic responses controlling the induction of adult diapause and the determination of seasonal form in the bean bug, Riptortus clavatus. Zool. Sci. 10: 983-990.

Nakamura, K. and H. Numata (1997) Seasonal life cycle of Aelia fieberi Scott (Hemiptera: Pentatomidae) in relation to the phenology of host plants. Ann. Entomol. Soc. Am. 90: 625-630.

Nakamura, K. and H. Numata (1998) Alternative life cycles controlled by temperature and photoperiod in the oligophagous bug, Dybowskyia reticulata. Physiol. Entomol. 23: 69-74.

Numata, H. and S. Kobayashi (1994) Threshold and quantitative photoperiodic responses exist in an insect. Experientia 50: 969-971.

Numata, H. and K. Nakamura (2002) Photoperiodism and seasonal adaptations in some seed-sucking bugs (Heteroptera) in central Japan. Eur. J. Entomol. 99: 155161.

Numata, H. and K. Yamamoto (1990) Feeding on seeds induces diapause in the cabbage bug, Eurydema rugosa. Entomol. Exp. Appl. 57: 281-284.

Panizzi, A. R., J. E. McPherson, D. G. James, M. Javahery and R. M. McPherson (2000) Stink bugs (Pentatomidae). In Heteroptera of Economic Importance (C. W. Schaefer and A. R. Panizzi eds.). CRC Press, Boca Raton, pp. 421474.

Perepelitza, L. V. (1969) The breeding of Dolycoris baccarum in the laboratory. Zool. Zh. 48: 757-759 (in Russian with English summary).

Tauber, M. J., C. A. Tauber and S. Masaki (1986) Seasonal Adaptations of Insects. Oxford University Press, New York. $411 \mathrm{pp}$.

Tomokuni, M., T. Yasunaga, M. Takai, I. Yamashita, M. Kawamura and T. Kawasawa (1993) A Field Guide to Japanese Bugs: Terrestrial Heteropterans. Zenkoku Noson Kyoiku Kyokai, Tokyo. 380 pp. (in Japanese). 